\title{
COMPREENDENDO O HORMÔNIO DO CRESCIMENTO NOS ÂMBITOS DA SAÚDE, DESENVOLVIMENTO E DESEMPENHO FÍSICO
}

Rômulo José Dantas Medeiros

Maria do Socorro Cirilo de Sousa

\section{Resumo}

$\mathrm{O} \mathrm{GH}$, também chamado de somatotropina, é um hormônio secretado pela hipófise anterior e é composto por uma cadeia simples de 191 aminoácidos. A principal função desencadeada por este hormônio é a promoção do crescimento de todo o corpo humano através da sua ação interventiva na formação protéica, multiplicação celular e diferenciação celular. Sua hipo e/ou hipersecreção é capaz de provocar anomalias físicas como o nanismo, gigantismo e em acromegalia em adultos e crianças. Referente ao metabolismo dos macro-nutrientes, ressalta-se que GH promove aumentos de síntese protéica, elevação dos níveis de lipólise e concomitante redução na utilização do carboidrato para produção de energia. E, no que concerne ao exercício físico, especificamente ao treinamento de força, dados advindos de estudos científicos não corroboram a prerrogativa que atribui ao $\mathrm{GH}$ o caráter de eficiência quanto à viabilização da hipertrofia muscular.

\section{Palavras-Chaves}

GH; Metabolismo energético; Treinamento; Doping.

\section{UNDERSTANDING THE GROWTH HORMONE IN HEALTH, DEVELOPMENT AND PHYSICAL PERFORMANCE PERSPECTIVES}

Rômulo José Dantas Medeiros

Maria do Socorro Cirilo de Sousa

\begin{abstract}
The human GH is a polypeptide hormone secreted by anterior pituitary chain of 191 amino acid that promotes growth of the entire body by affecting tissue formation, through cell multiplication and cell differentiation. Its hipo or hipersecretion caused abnormalities of growth as a dwarfism, gigantism and acromegaly in adults and children. Also, the GH affected the macro-nutrients metabolism enhancing protein synthesis, using up fat stores and decreasing carbohydrate utilization for energy. Additionally, related to exercise, specifically strength training, scientific data do not agreement with prerogative that affirm the GH as an efficient facilitate factor to muscle hypertrophy.
\end{abstract}

\section{Key-Words}

GH; Energetic metabolism; Training; Doping. 


\section{INTRODUÇÃO}

O sistema endócrino e seus respectivos componentes, os hormônios, integram e regulam inúmeras funções do organismo do ser humano, possibilitando a este estabilidade e equilíbrio ao seu "meio" interno orgânico (McARDLE et al., 2003, p.420). É através do mencionado sistema que se estabelece a regulação do volume sanguíneo, pressão arterial, diferenciação sexual, desenvolvimento, reprodução, digestão, sensação de fome e saciedade, e outros aspectos da função existencial humana (LEHNINGER et al., 2004, p. 881).

Segundo Mcardle et al. (2003, p. 421), o sistema endócrino é composto por três elementos principais, que se categorizam da seguinte forma: as glândulas, subdividas em endócrinas e exócrinas, que são os locais onde são sintetizados e se localizam armazenados minúsculos mensageiros químicos chamados de hormônios. Estes, por conseguinte, concretizam-se como os "agentes" que atuam e intervém nos órgãos/receptores/células-alvo que, por sua vez, se estabelecem como locais que terão suas reações celulares modificadas.

Dentre os citados elementos, destacam-se os hormônios, que tem sua produção, concentração, secreção e conseqüente ação regulada por meio de vários mecanismos. Entre esses, ressalta-se os de estimulação hormonal, humoral e neural. No primeiro caso, os hormônios influenciam a secreção de outros hormônios. Em âmbito humoral, a liberação hormonal decorre das oscilações presentes nos níveis de certos íons e nutrientes do sangue, da bile e em outros líquidos corporais. E na estimulação neural, como a própria categorização propõe, a liberação dos hormônios é afetada por atividades de caráter e origem neural (McARDLE et al. 2003, p. 424).

Quanto a sua composição, os referidos hormônios são classificados em três principais classes, ficando assim, de acordo com Guyton e Hall (2006, p. 906), categorizados como: protéicos e polipeptídios, onde incluem-se hormônios secretados pela hipófise anterior e posterior, pâncreas, glândula paratireóide, entre outras; os esteróides, que abrangem os liberados pelo córtex adrenal, pelos ovários, testículos e placenta; e por último, os derivados de aminoácidos, que constituem os secretados pela glândula tireóide e pela medula supra-renal.

Neste momento, objetivando-se estabelecer uma análise mais específica, salienta-se os hormônios peptídicos e protéicos e sua principal glândula, a pituitária. A glândula pituitária, subdividida em hipófise anterior e posterior, localiza-se debaixo da base do cérebro e é responsável pela secreção de seis 
hormônios principais. Cada um desses hormônios tem sua secreção regulada por um fator de liberação e inibição provenientes da glândula mestre, o hipotálamo (McARDLE et al. 2003, p. 428). Observa-se que é da porção anterior da referida glândula, que provém os hormônios que apresentam um "papel" de maior controle das funções orgânicas corporais, podendo-se destacar, o hormônio do crescimento (GH) (GUYTON; HALL, 2006, p. 918).

Seguindo-se o exemplo do "supracitado" parágrafo, que estabelece uma análise mais restritiva, convenciona-se a partir deste momento o objetivo de revisar aspectos que norteiam a ação do hormônio do crescimento $(\mathrm{GH})$. Enfatizando-se que esta revisão tem um caráter pertinente por visar, entre outros propósitos, "trazer a tona" informações que desmistificam afirmações associadas à relação existente entre o GH, exercício/treinamento físico e o doping.

\section{HORMÔNIO DO CRESCIMENTO (GH)}

O GH, também chamado de somatotropina, é um hormônio secretado pela hipófise anterior e é composto por uma cadeia simples de 191 aminoácidos. A principal função desencadeada por este hormônio é a promoção do crescimento de todo o corpo (neste caso humano) através da sua ação interventiva na formação protéica, multiplicação celular e diferenciação celular (GUYTON; HALL, 2006, p. 918). Segundo Takarada et al. (2000), citado por Gentil (2005, p. 40), uma das principais características do GH é a pulsatilidade, pois sua concentração pode variar em até 290 vezes em poucos minutos. O mesmo autor também evidencia que o citado hormônio apresenta como principais estímulos de liberação o sono, a hipoglicemia, refeições ricas em proteínas, estresse (dor, calor, ansiedade), exercício e outros agentes (serotonina, estrógenos, adrenalina, entre outros).

Dentre os hormônios que compõem a hipófise anterior, o GH é o que apresenta maior peculiaridade em sua forma de atuação. Os demais hormônios exercem, predominantemente, suas "intervenções" estimulando a ação de outras glândulas, incluindo a glândula tireóide, córtex adrenal, ovários, testículos, entre outros. Em contraste, a função do GH efetiva-se diretamente nos seus "locais-alvos", ou seja, em todos os tecidos do corpo (GUYTON; HALL, 2006, p. 922).

Fundamentando-se nos dados encontrados em estudos realizados por Skottner (1987), Gree et al. (1985) e Adam e McCue (1998), Gentil (2005, p. 41) afirma que, basicamente, existem duas hipóteses para 
explicar a atuação do hormônio de crescimento. A primeira é a hipótese da somatomediação, contraposta a explicação da ação direta do GH nos "locais-alvos", que associa o crescimento tecidual aos fatores de

crescimento tipo insulina: " $\mathrm{O}$ GH chegaria ao fígado e tecidos periféricos, causando a liberação e produção dos fatores de crescimento tipo insulina (IGFs), podendo também aumentar a quantidade de receptores para estes peptídeos, o que prolongaria a meia-vida dos IGFs" (GENTIL, 2005, P. 41).

E a segunda é a hipótese do duplo efeito: "Segundo esta teoria, além de agir indiretamente, o próprio GH atuaria diretamente nas células, como de crescimento, provavelmente devido à diferenciação das células satélites (GREE et al. 1985; ADAM; McCUE, 1998, p. 41).

Diante da supracitada hipótese da somatomediação, torna-se importante "abrir um parêntese", para ressaltar que os fatores de crescimento tipo insulina (IGFs), têm sua secreção e ação intimamente associadas ao GH. Kahn et al. (2002) citado por Kramer e Ratamess (2006), afirma que os IGFs, especificamente o IGF-1, são secretados e produzidos pelo fígado em resposta a estimulação do GH, com o intuito de promover a síntese do DNA. Por conseguinte, Gentil (2005, p. 41) ao citar Skottner (1987), evidencia que "quanto à liberação do IGF-1, o hormônio do crescimento parece ser um fator endócrino muito eficiente, visto que aplicar GH eleva a quantidade sérica de IGF-1 cerca de 50 vezes mais do que injetar o próprio IGF-1".

\section{EFEITOS DA HIPO E HIPER SECREÇÃO DE GH}

$\mathrm{O}$ GH, por se concretizar como um fator de alta importância quando a temática é desenvolvimento corporal, torna-se foco de pesquisas que objetivam investigar distúrbios associados ao crescimento. Para McArdle et al.. (2003, p. 426), deficiências e estados de hipersecreção de GH são as principais causas para a existência de anormalidades como: nanismo em crianças (hiposecreção), gigantismo em crianças e acromegalia em adultos (hipersecreção).

Quanto à deficiência do respectivo hormônio, estudos de revisão, como o realizado por Primus e Mullis (2007), mostram que o déficit na produção de GH pode se estabelecer de várias formas, devido a distintas "falhas" genéticas, sendo estas por sua vez, capazes de promover "desordens" físicas caracterizadas diferentemente. Corroborando tais afirmações, os mesmos autores demonstram, em forma de quadros e tabelas, irregularidades na produção de $\mathrm{GH}$, associadas a modificações genéticas relacionadas a fatores de transcrição como: Pit1, PROP1, HESX1, LHX3, LHX4, entre outros. E, concomitantemente, destacam 
também que indivíduos com alterações genéticas e deficientes secreções de $\mathrm{GH}$, podem a vir caracterizarse por baixas estaturas, níveis circulantes reduzidos do referido hormônio, crescimentos desacelerados, taxas de desenvolvimento corporal equivalente a $25 \%$ quando comparadas a indivíduos saudáveis, significantes estados de redução de massa óssea, entre outros.

Por outro lado, diagnósticos de crescimento tecidual exagerado são evidenciados quando encontram-se níveis elevados de secreção de GH. O gigantismo pituitário e/ou acromegalia, que se estabelecem como as principais disfunções evidenciadas pela hiperliberação de GH, são doenças raras que, segundo Ayuk e Sheppard (2006), apresentam incidência anual de 3-4 pessoas por milhão de indivíduos, e demonstram significante associação com índices de morbidade e mortalidade.

\section{GH E O METABOLISMO DOS LIPÍDIOS, PROTEÍNAS E CARBOIDRATOS}

Além da ação sobre o crescimento corporal, o GH exerce específicas funções metabólicas, podendo promover aumentos de síntese protéica, elevação da mobilização de lipídeos para produção de energia e redução da utilização da glicose (GUYTON; HALL, 2006, p. 922). No que concerne a síntese protéica, os mesmos autores afirmam que a mesma é acrescida devido aos seguintes "aumentos": translação do RNA que, consequentemente, eleva a síntese por meio dos Ribossomos; transcrição nuclear do DNA para a forma do RNA; e redução do catabolismo protéico e dos aminoácidos.

Em um estudo de revisão realizado por Moller et al. (2007), constata-se que o GH interfere positivamente na síntese protéica quando há infusão do mesmo a nível local da musculatura (FRYBURG et al.., 1991; COPELAND; AIR, 1994b). Em contraposição, a infusão do GH a nível sistêmico não demonstra elevar os níveis da síntese de proteínas (COPELAND; NAIR, 1994a; ZACHWIEJA et al. 1994). Quanto aos lipídeos, Guyton e Hall (2006, p. 923) demonstram que o GH aumenta o processo de lipólise que, por conseqüência, eleva a concentração sanguínea de ácidos graxos. Adicionalmente, o GH promove acréscimos na conversão dos ácidos graxos em acetil-coezima A e, dessa forma, possibilita sua subseqüente utilização na produção de energia.

O metabolismo dos carboidratos, por sua vez, sofre múltiplos efeitos advindos do $\mathrm{GH}$, incluindo o aumento da produção de glicose por parte do fígado e elevação dos níveis de secreção do hormônio insulina (GUYTON; ALL, 2006, p. 923). Ou seja, o GH promove reduções na utilização dos carboidratos. Doravante, ao promover aumentos nos níveis séricos de glicose e insulina, o GH acaba 
incorporando um adjetivo bastante propositivo: hormônio diabetogênico. No estudo de revisão realizado por Jorgensen et al. (2007), encontram-se dados que afirmam que a excessiva secreção de GH pode produzir distúrbios metabólicos bastante similares aos encontrados em indivíduos que apresentam diabetes tipo II (não-insulino dependente).

\section{GH E EXERCÍCIO FÍSICO}

$\mathrm{Na}$ literatura clássica é possível visualizar de maneira bastante clara, a existência de um consenso que afirma haver elevações dos níveis de $\mathrm{GH}$, em decorrência da aplicação de exercícios, devido à necessidade de se estabelecer "ambientes" propícios para o crescimento e fortalecimento dos músculos, dos ossos e tecidos conjuntivos (McARDLE et al. 2003, p. 429). Isto é, o GH como resposta ao exercício e/ou treinamento físico, apresenta como principal função a síntese tecidual (por exemplo: hipertrofia muscular). No entanto, estudos de revisão mais recentes, como o realizado por Gentil (2005), tem demonstrado que tal relação linear não é tão simples de ser estabelecida.

\section{TREINAMENTO DE FORÇA E GH}

No âmbito do senso comum, o GH sempre esteve associado aos ganhos de força e massa muscular proporcionados pelo treinamento de força. No entanto, com advento e desenvolvimento da pesquisa científica voltada a esse tipo de treino, estudos vem encontrando novos e, ao mesmo tempo, interessantes dados que merecem ser analisados de uma maneira mais aprofundada.

A relação existente entre o $\mathrm{GH}$, a hipertrofia e força muscular, vem sendo "fragilizada" pelas hipóteses levantadas em estudos realizados por autores como Taaffee et al. (1994). Yarasheski et al. (1995) e Deyssig et al. (1998). Nessas hipóteses, verifica-se que o GH não é eficiente em aumentar a seção transversal das proteínas contráteis componentes dos músculos dos seres humanos. Nos mencionados estudos, encontrou-se que ao se combinar GH e treinamento com pesos, ocorreram aumentos de massa muscular, no entanto, sem haver elevações nos níveis de força. Tais achados evidenciam que o aumento de peso corporal advindo do uso do GH seria, provavelmente, proveniente de proteínas não-contráteis e de retenção de fluidos.

Adicionalmente, Lange et al. (2002) citado por Gentil (2005, p. 42), acompanharam quatro grupos (controle, GH, GH + treinamento de força, placebo + treinamento de força) e verificaram, por meio dos exames DEXA e ressonância magnética, "que o uso de GH não favorece de maneira significativa o ganho de massa muscular, independente de ser utilizado isolada ou concomitantemente ao treino de força". 


\section{A CCINÉTICA DO GH MONITORADA NO ESPORTE: O CASO DO DOPING}

$\mathrm{O} \mathrm{GH}$, como já foi explicitado no presente texto, é um hormônio secretado naturalmente pela hipófise anterior. Devido à sua função de síntese tecidual, desde a década de 80 até os dias atuais, uma forma sintética do referido hormônio ( $\mathrm{GH}$ recombinado humano - rhGH) vem sendo utilizada clinicamente e têm apresentado positivos resultados no tratamento de pacientes com deficiências de GH (por exemplo: nanismo). Dentre os efeitos positivos, podem-se destacar ações anabólicas capazes de promover aumentos de massa muscular e reduções dos níveis de gordura corporal. Assim, diante de tais propriedades, muitos atletas, visando obter os mencionados resultados anabólicos, começaram a fazer uso do GH objetivando alcançar maiores níveis de performance física (EHRNBORG et al. 2000).

Segundo Powrie et al.. (2007), o GH vem sendo efetivamente usado como recurso ergogênico desde o ano de 1988, e foi nos últimos dez anos que o seu uso aumentou drasticamente, independente dos relatos que o afirmam como a "droga" mais cara a ser utilizada. Adicionalmente, os mesmos autores informam que a popularização do respectivo hormônio pode ser traduzido em um ditado popular que o afirma como "eficiente, difícil de ser detectado em exames antidoping e não causador de efeitos colaterais".

Dentre os desportistas, evidencia-se que os fisiculturistas são os atletas que mais fazem uso de GH, pois sua modalidade exige altos níveis de massa muscular e "baixíssimos" de gordura (GREGORY et al. 2007). Diante das exigências desse esporte, pode-se perceber o surgimento de um paradoxo: o GH é utilizado para maximizar a hipertrofia muscular, no entanto, inúmeros estudos (anteriormente citados na seção treinamento de força e $\mathrm{GH}$ ) não o classificam como eficiente para tal fim. Em três "polêmicas" produções voltadas para o estudo da relação anabólicos-fisiculturistas, Guimarães Neto (2005a, 2005b, 2005c) destaca que "fora do meio científico", atletas "julgam" o GH como uma droga eficiente. Adicionalmente, o mesmo autor afirma que quando a temática é treinamento físico, de qualquer modalidade, o conhecimento empírico atribuído ao cotidiano da prática desportiva, não deve ser abnegado em detrimento do conhecimento científico.

\section{CONCLUSÕES}

Diante do exposto, constata-se que o GH é um hormônio de primordial importância para o crescimento e desenvolvimento corporal do ser humano. No entanto, quanto ao exercício e treinamento físico, sua possível "benéfica" interferência (aumento de massa muscular e redução de gordura) ainda apresenta-se de maneira controversa. Tendo assim, concomitantemente, conhecimentos empíricos que o afirmam 
como uma boa ferramenta de uso, e, em contraposição, conhecimentos advindos de pesquisas que não atribuem ao GH essa características de eficácia.

\section{REFERÊNCIAS}

ADAM, G. R; McCUE, A. S. Localized infusion of IGF-1 results in skeletal muscle hypertrophy in rats. Journal of Applied Physiology. v. 84, n. 5, p. 1716-1722, 1998

AYUK, J; SHEPPARD, M. C. Growth hormone and its disorders. Postgraduate Medical Journal. v.82, n.963, p. 24-30, 2006.

COPELAND, K. C; NAIR, K. S. Acute growth hormone effects on amino acid and lipid metabolism. Journal of Clinical Endocrinology and Metabolism, v. 78, n. 1, p. 104-1047, 1994a.

COPELAND, K. C; NAIR, K. S. Recombinant human insulin-like growth factor-I increases forearm blood flow. Journal of Clinical Endocrinology and Metabolism. v. 79, n. 1, p. 230-232, 1994b.

DEYSSIG, R. et al. Effect of growth hormone treatment on hormonal parameters body composition and strength in athletes. Acta Endocrionology, v. 128, n. 4, p: 313-318, 1998.

EHRNBORG, C; BENGTSSON, B; ROSÉN, T. Growth hormone abuse. Baillière's Clinical Endocrinology and Metabolism, v. 14, n. 1, p. 71-77, 2000.

FRYBURG, D. A; GELFAND, R. A; BARRETT, E. J. Growth hormone acutely stimulates forearm muscle protein synthesis in normal humans. American Journal of Physiology, Endocrinology and Metabolism. v. 3, n. 60, p. 99-104 1991.

GENTIL, P. Bases Cientificas do treinamento de hipertrofia. Rio de Janeiro: Sprint, 2005.

GREE, H; MORIKAWA, M; NIXON, T. A dual effector theory of growth hormone action. Differentiation, v. 29, n. 3, p. 195-198, 1985.

GREGORY, A. J. M.; FITCH, R. W. Sports medicine: performance-enhancing drugs. Pediatric Clinics of North America. v. 4, p. 797-806, 2007.

GUIMARAES NETO, W. M. Musculação: anabolismo total. 7. ed. Guarulhos: Phorte, 2005a. . Musculação Além do Anabolismo. 2. ed. Guarulhos, São Paulo: Phorte, 2005b. . Guerra metabólica. Guarulhos: Phorte, 2005c.

GUYTON, A. C.; HALL, J. E. Textbook of medical physiology. 11. th ed. Philadelphia: Elsevier/ Saunders, 2006. 
JORGENSES, J. O. L. et al. Effects of growth hormone on glucose and fat metabolism in human subjects. Endocrinology and Metabolism Clinics of North America. v. 36, p. 75-87, 2007.

LANGE, K. H. et al. administration changes myosin heavy chain isoforms in skeletal muscle but does not augment muscle strength or hypertrophy, either alone or combined with resistance exercise training in healthy elderly men. Journal of Clinical Endocrinology and Metabolism, v. 87, n. 2, p. 513-523, 2002. LEHNINGER, A. L; NELSON, D. L; COX, M. M. Principles of biochemistry. 4. ed. New York: W. H. Freeman, 2004.

MCARDLE, W. D; KATCH, F. I; KATCH, V. L. Fisiologia do exercício energia, nutrição e desempenho humano. 5. ed. Rio de Janeiro: Guanabara Koogan, 2003.

POWRIE, J. K. et al. Detection of growth hormone abuse in sport. Growth Hormone and IGF Research, v.17, n. 3, p. 220-226, 2007.

PRIMUS, E; ULLIS, M. D. Genetics of growth hormone deficiency. Endocrinology and Metabolism Clinics of North America, v. 36, p. 17-36, 2007.

SKOTTNER, A. et al. Recombinant human insulin-like growth factor: testing the somatomedin hypothesis in hypophysectomized rats. Journal of Endocrinology, v. 112, n. 1, p. 112-123, 1987.

TAAFEE, D. R. et al. Effect of recombinant human growth hormone on the muscle strength response to resistance exercise in elderly men. Journal of Clinical Endocrinology and Metabolism, v. 79, n. 5, p. 1361-1366, 1994.

TAKARADA, Y. et al. Rapid increase in plasma growth hormone after low-intensity resistance training with vascular occlusion. Journal of Applied Physiology. v. 86, n. 1, p. 61-65, 2000.

YARASHESKI, K. E. et al. Effect of growth hormone and resistance exercise on muscle growth and strength in older men. American Journal of Physiology. v. 268, n. 2, p. 268-276, 1995.

ZACHWIEJA, J. J.; BIER, D. M.; YARASHESKI, K. E. Growth hormone administration in older adults: effects on albumin synthesis. American Journal of Physiology, v. 266, p. 840-844, 1994. 
Rômulo José Dantas Medeiros

Universidade Federal da Paraíba

Maria do Socorro Cirilo de Sousa

Universidade Federal da Paraíba

\section{Referência do artigo:}

\section{ABNT}

MEDEIROS, R. J. D. Sousa, M. S. C. Compreendendo o hormônio do crescimento nos âmbitos da saúde, desenvolvimento e desempenho físico

\section{APA}

Medeiros, R. J. D., Sousa, M. S. C. (2008) Compreendendo o hormônio do crescimento nos âmbitos da saúde, desenvolvimento e desempenho físico. Conexões, 6(3), 68-77

\section{VANCOUVER}

Medeiros RJD, Sousa MSC. Compreendendo o hormônio do crescimento nos âmbitos da saúde, desenvolvimento e desempenho físico. Conexões; 2008; 6(3): 63-77.

Artigo recebido: $31 / 07 / 08$

Aceito: 20/10/08 